\title{
Fenomenología del prejuicio
}

\author{
FERNANDO MONTERO MOLINER \\ Universidad de Valencia
}

Este trabajo expone la defensa del "pre-
juicio» llevada a cabo por Gadamer,
mostrando su efectividad histórica y
confrontándola con la crítica husserlia-
na del «prejuicio" desde el apriorismo.
Se pone de relieve, además, la historicidad del "mundo de la vida" y su incidencia en la teoría del a priori, para terminar con un estudio de la racionalidad del a prioni y la facticidad del prejuicio.

\section{Planteamiento del problema}

Es bien sabido que el problema del «prejuicio» ha sido tratado por Gadamer y por Husserl, aunque de formas muy distintas. Mientras constituye un elemento teórico positivo de la hermenéutica de Gadamer, suscita la más decidida oposición por parte de la fenomenología de Husserl. Pues en ella el "prejuicio» viene a ser la antítesis de lo a priori. $\mathrm{Y}$, por consiguiente, toda la relevancia que puedan tener en su método las funciones de la conciencia o las objetividades intencionales, las esencias y los principios que pretenden valer a priori, supone un rechazo de los prejuicios que pudieran introducirse en cualquier sistema teórico o práctico.

Este trabajo se propone acortar distancias entre las posiciones adoptadas por Husserl y Gadamer con respecto al "prejuicion, tal vez porque tome en serio las solemnes declaraciones que hizo el segundo en Verdad y método, afirmando su deuda con el método fenomenológico practicado por Husserl. Para ello intentará examinar si es posible considerar lo a priori como una forma peculiar de prejuicio. Lo cual supondría que muchos de los elementos teóricos que constituyen lo a prioni podrían ser transplantados a la teoría de Gadamer sobre el prejuicio, enriqueciéndola de alguna manera. Pero también habrá que admitir que otras características de éste, en especial su vinculación con la historia, deberán ser trasladadas a la teoría husserliana del a priori. Esta operación puede ser facilitada por la contribución de La crisis de las ciencias europeas que, como es sabido, constituye una importante revalorización de la historicidad dentro del método fenomenológico de Husserl. Sin embargo, ello deja abierto un interrogante fundamental: ¿en qué medida una interpretación de lo a prion como un prejuicio que esté condicionado por la historicidad de la subjetividad puede afectar seriamente la validez universal y necesaria de ese a prio- 
ri? ¿hasta qué punto será posible seguir hablando de un a priori que, a su manera, comparta la historicidad de los prejuicios?

\section{Teoria gadameriana del prejucicio}

Aunque la teoría de Gadamer sobre el prejuicio es cronológicamente posterior a la de Husserl, la expondré en primer lugar porque su comprensión es más fácil en tanto que no está sometida a un giro temático, como es posible que ocurra con la de Husserl a partir de la aparición en su obra del mundo de la vida concreto en La crisis de las ciencias europeas. Es decir, constituye un punto de referencia más simple.

Gadamer aborda el tema del prejuicio en el segundo apartado («Fundamentos para una teoría de la experiencia hermenéutican) de la segunda parte de Verdad y método, enlazándolo con la teoría heideggeriana de la "comprensión", en tanto que ésta arrastra consigo una conciencia histórica de los precedentes que abrieron paso a lo que ahora se comprende. «Sólo este reconocimiento del carácter esencialmente prejuicioso de toda comprensión confiere al problema hermenéutico toda la agudeza de su dimensión.» Pues la «comprensión» o la «interpretación» sólo podrán acaecer en la medida en que operen y se manifiesten o pongan al descubierto los prejuicios que condicionen el conocimiento de una cosa, de un texto o de una situación cualquiera. En todo aquello que se comprende hay una historia previa, la que concierne a la cosa comprendida, a su entidad concreta o a todo aquello que se relaciona con ella y que hace posible su comprensión.

Por consiguiente, advierte Gadamer que «un análisis de la historia del concepto muestra que sólo en la llustración adquiere el concepto de prejuicio el matiz negativo que ahora tiene. En sí mismo 'prejuicio' quiere decir un juicio que se forma antes de la convalidación definitiva de todos los momentos que son objetivamente determinantes". Es cierto que en el lenguaje jurídico "prejuicio» significa un juicio dañino o desventajoso que introduce supuestos o valoraciones injustificadas que perturban el fallo de la sentencia. Pero, si se prescinde de esa acepción judicial, «prejuicio» no tiene por qué significar necesariamente un juicio falso o perturbador para la comprensión de aquello que es prejuzgado. Dependerá de los casos el que tergiverse esa comprensión o coopere positivamente con ella.

Es manifiesto que la actitud positiva que Gadamer adopta con respecto a los prejuicios está basada en su valoración de la historicidad de la existencia humana. «Si se quiere hacer justicia al modo de ser finito e histórico del hombre es necesario llevar a cabo una drástica rehabilitación del prejuicio y reconocer que hay prejuicios legitimos." Nuestra conciencia no puede ser concebida como estrictamente actual, como si sólo pesara en ella lo que en el presente se le manifiesta o lo que expresamente la condi- 
ciona en la actualidad. Lo mismo que la comprensión está constituida por una previsión de posibilidades que emergen de lo actual, está también determinada por la vigencia de lo retenido en experiencias anteriores, por lo que «ya se sabe» en relación con lo que ahora se juzga y que, por consiguiente, prejuzga lo comprendido en el presente. Por tanto, los prejuicios encauzan nuestra apertura al mundo, condicionan previamente toda experiencia y toda interpretación de cualquier cosa.

Sin embargo, es evidente que la defensa del prejuicio que Gadamer realiza depende también de su alejamiento de los motivos racionalistas que están en la base de la actitud ilustrada. Con otras palabras, la prevención de la Ilustración contra los prejuicios deriva del hecho de que este término arrastra unas connotaciones que dan cierta validez a lo que desborda una estricta racionalidad. El "prejuicion condenado por los ilustrados es el que tiene vigencia aunque no sea estrictamente racional o «legítimo». Esto ocurre con la mayor parte de los prejuicios, sin necesidad de que por ello sean falsos o erróneos. Y este es el motivo por el que Gadamer sale en defensa de los prejuicios: porque estima que buena parte de nuestra comprensión de las cosas depende de juicios previos que tienen validez para el que los prejuzga, aunque no tenga de cllos una justificación racional rigurosa. Sería imposible juzgar la historia real del hombre y su comprensión de las cosas si sólo contaran los prejuicios legitimos, es decir, los que se conciben y formulan con estricta racionalidad. La interpretación de cualquier momento histórico o de los hechos que en él acaecen exige la captación de los prejuicios de toda suerte que han calado en la situaciones de ese momento y que permiten la comprensión de sus sucesos, de sus testimonios. Ahora bien, si la Ilustración reservó el término "prejuicio» para el que es racionalmente «ilegítimon, la constatación que hace Gadamer de su relevancia en el sentido de la historia y en la comprensión de los hechos históricos tenía que' pasar por alto esa calificación negativa y debía formularse simplemente como una "rehabilitación del prejuicio". Más aún, «la superación de todo prejuicio» proclamada por la tlustración, «revela ser ella misma un prejuicio cuya revisión hará posible una comprensión adecuada de la finitud que domina no sólo nuestro ser humano sino también nuestra conciencia histórica». Y cuando, unas páginas abajo, afirme que la comprensión de la índole histórica del hombre arrastra consigo una rehabilitación del prejuicio y el reconocimiento de que hay "prejuicios legítimos", con esa "legitimidad" no alude estrictamente a la racionalidad de los prejuicios que pueden funcionar como principios lógicos en una implícita deducción de los hechos, sino a la índole de todo prejuicio que condiciona realmente, de modo efectivo, el sentido de un hecho, de un testimonio histórico. La «historia efectiva» (die Wirkungsgeschichte) sólo es comprensible y sus productos sólo pueden ser interpretados mediante el recurso a prejuicios cuya «legitimidad» no se basa en que sean principios 
lógicos de una presunta racionalidad deductiva, sino en su efectivo condicionamiento de hechos que, por ello mismo, los llevan grabados en su trama inteligible.

\section{El rechazo del prejuicio por Hussert}

La relación entre el prejuicio y la historicidad en la filosofía hermenéutica de Gadamer puede hacer pensar que en la obra de Husserl debería darse una doble actitud hacia el problema del prejuicio en la medida en que haya variado su valoración de la historia. En efecto, ésta pasa por dos etapas claramente diferenciadas. La primera corresponde al período de las Investigaciones logicas y las Ideas para una fenomenología pura. La segunda pertenece a la aparición de mundo de la vida concreto en la quinta de las Meditaciones cartesianas y en La crisis de las ciencias europeas.

Es decir, la primera etapa es la de un Husserl escasamente interesado por el problema de la historia, como no sea para combatir el historicismo en La filosofía como ciencia rigurosa. La segunda etapa supone un giro radical en la actitud de Husserl respecto a la Historia. Aunque en las páginas venideras nos ocupemos con más detalle de algunos de sus aspectos, en especial los concernientes al mundo de la vida, por cuanto inciden directamente en el problema del prejuicio, se puede adelantar que en este momento Husserl adquirió una viva conciencia de la importancia que tiene la historicidad en su acepción más amplia para la constitución de cualquier movimiento filosófico, incluso el de la propia fenomenología. Al plantear en su primera parte el alcance de la crisis que aqueja a la cultura europea, dice que «sólo mediante el esclarecimiento del sentido unitario de la historia [de nuestra humanidad actual], un sentido que le es propio desde su origen junto con la tarea, renovadamente planteada que, como fuerza motriz, pone en obra las tentativas filosóficas, podremos acceder a la comprensión de nosotros mismos y, con ella, a un genuino sostén interior». $\mathrm{Y}$ añade unas páginas más tarde, al precisar que «como filósofos somos herederos del pasado en cuanto a la fijación de objetivos que la palabra 'filosofia' remite, en cuanto a sus conceptos, problemas y métodos»: «Está claro [...] que se requieren cuidadosas y exhaustivas investigaciones retroactivas de tipo histórico y crítico para alcanzar, antes de toda posible decisión, una autocomprensión radical».2

Pues bien, si la historia se convierte en un terna central en la última etapa del pensamiento de Husserl, ¿̇en qué medida ha podido suscitar una actitud positiva en su tratamiento del prejuicio, en tanto que la historicidad suponga la transmisión y herencia de creencias y tradiciones que constituyan prejuicios determinantes para el desarrollo de la vida humana en cualquiera de sus manifestaciones? En definitiva, el reconocimiento de que somos herederos del pasado y de que éste condiciona decisivamente todo 
cuanto realizamos, ¿no tenía que suscitar una rehabilitación de los prejuicios, en el momento en que, con este término, se hiciera mención del legado del pasado que anticipa los elementos fundamentales con que ejecutamos nuestras tareas actuales y abrimos paso a las futuras?

Sin embargo, la esperanza de hallar así un elemento doctrinal coincidente entre Husserl y Gadamer se esfuma en cuanto se realiza un balance de toda su obra. Es decir, no sólo en sus primeros escritos fenomenológi$c o s$, en las Investigaciones lógicas, sino en los de sus últimos años, en $L a$ crisis de las ciencias europeas, la actitud de Husserl frente al prejuicio es radicalmente crítica. Esto nos obliga, en primer lugar, a precisar lo que fue para ćl, a diferencia de Gadamer, el prejuicio. En segundo lugar, habrá que decidir en qué medida se excedió en su condena de los prejuicios o en la correlativa consideración de que los fundamentos del conocimiento humano son de indole absolutamente distinta, principios lógicos formales o trascendentales, leyes esenciales, que no tienen nada en común con los prejuicios. Pues, en definitiva, si Husserl descalificaba a los prejuicios como elementos reguladores de la ciencia fenomenológica y de la verdad en sentido riguroso es porque asignaba esas funciones a unas ideas cuya validez a priori quedaba por encima de los avatares de la historia y de la contingencia que tienen los prejuicios que corren a lo largo de su curso.

La existencia de una contimuidad en el rechazo husserliano de los prejuicios justifica que se atienda brevemente su planteamiento inicial en las Investigaciones lógicas, por tratarlo allí desde la perspectiva de la lógica formal que establece los principios rectores del enunciado. En cambio, en sus obras posteriores y, en especial, en La crisis de las ciencias europeas, el prejuicio es combatido desde la lógica trascendental que toma en consideración la totalidad del mundo como correlato intencional de la subjetividad.

Por otra parte, el tratamiento del prejuicio desde la lógica formal del enunciado tiene la ventaja de que la piedra de toque para denunciar la existencia de un prejuicio es la vigencia de los principios lógicos que evitan el "contrasentido", es decir, los principios de no-contradicción, de identidad, del tertio excluso, de los modi ponens y tollens, etc. Por consiguiente, el prejuicio que más preocupó a Husserl desde esta perspectiva fue el representado por el psicologismo, es decir, el que sostuvo que las leyes lógicas son leyes psicológicas. Sin entrar ahora en una discusión sobre la validez de los argumentos husserlianos, lo que importa destacar es su tesis de que el psicologismo era un prejuicio inaceptable desde el momento en que falseaba la índole formal de la lógica al intentar reducirla a la psicología, arruinando con ello la validez a priori de los principios que rigen la corrección del pensamiento enunciativo. El desconocimiento de la pureza lógica de estos principios, es decir, de su irreductibilidad a cualquier balance de experiencias psicológicas, el empeño de eliminar el apriorismo cediendo a 
la presión de las convicciones empiristas que niegan todo derecho a lo que pretende tener una validez universal y necesaria, todo ello es un prejuicio que, según Husserl, falsea radicalmente el sentido y la función de la lógica formal.

Por ello el capítulo VIII de "Los prolegómenos a la lógica pura», con que comienzan las Investigaciones lógicas, se titula «Los prejuicios psicologistas». Es interesante anotar que cuando, once años más tarde, en La filosofia como ciencia rigurosa, Husserl reanude sus ataques contra el psicologismo, presente sus prejuicios bajo el título de «naturalismo». Lo cual hace pensar que ahora ya no se trata sólo de impugnarlos desde la perspectiva de la lógica formal, sino de una incipiente lógica trascendental, que protesta contra la reducción de la subjetividad o del espíritu a una naturaleza cognoscible mediante leyes meramente empíricas.

Pero las últimas obras que Husserl publicó, las Meditaciones cartesianas y La crisis de las ciencias europeas, son las que manifiestan una mayor hostilidad hacia los prejuicios. Continuando el giro iniciado en La filosofía como ciencia rigurosa, ahora ya no se trata de los prejuicios de la lógica formal, que falsean la validez de los principios ontológicos que rigen el enunciado, sino de los que corresponden a la lógica trascendental y, por tanto, falsean la vinculación entre la subjetividad y el mundo. Con otras palabras, son prejuicios que conciernen a la fenomenología misma como método y como sistema, desde el momento en que tergiversan el significado de sus principios fundamentales, los que conciernen a la relación intencional que media entre la subjetividad trascendental y el mundo.

Es interesante destacar que este recrudecimiento de la impugnación contra el prejuicio tiene lugar cuando la fenomenología husserliana gana una conciencia más viva de su situación histórica. A diferencia de Gadamer, que se sintió comprensivo hacia los prejuicios en tanto que constituían una pieza fundamental del proceso histórico y de la vigencia del pasado, Husserl manifestó un mayor recelo hacia ellos conforme se planteó con más agudeza la situación de la fenomenología en la historia y se percató de la novedad que suponía frente a todo el pensamiento pretérito. Con otras palabras, si en Gadamer el prejuicio constituye un elemento positivo que manifiesta la presencia fecunda del pasado en el presente, en Husserl tiene un significado negativo: la fenomenología podía constituir el desenlace feliz de la historia del pensamiento humano en tanto que se liberara de los prejuicios que habían dominado hasta ese momento en la filosofía pretérita arruinando sus logros.

Por ello las Meditaciones cartesianas, después de afirmar el mérito de la obra de Descartes como prototipo de la reflexión filosófica, plantean en el segundo parágrafo la "necesidad de un comienzo radical de la filosofía": "¿No debiera pertenecer más bien al sentido fundamental de la genuina filosofía la exigencia, presuntamente exagerada, de una filosofía dirigida a 
la extrema supresión concebible de prejuicios, una filosofía que se configura con efectiva autonomía a partir de evidencias últimas producidas por ella misma y, en consecucncia, absolutamente autorresponsable?", ${ }^{3}$ Ello significa, como dice en el parágrafo siguiente, que «comenzamos de nuevo, por tanto, cada uno para sí y por sí, con la decisión de filósofos que comienzan de un modo radical dejando fuera de juego, por de pronto, todas las convicciones - y entre ellas también todas nuestras ciencias- que hasta ahora tenían validez para nosotros $» .^{4}$

Pero el prejuicio cartesiano tiene consecuencias de más alcance que la simple evidencia del ego como la de un axioma matemático que facilitase un seguro "punto de partida» para todo el saber humano. El riesgo mayor, que lo constituye propiamente como un "prejuicio», es que arrastre consigo toda una interpretación ontológica que vaya mucho más allá de la estricta evidencia de la conciencia. A ello alude Husserl cuando dice unas líneas más abajo: «Lamentablemente, esto es lo que sucede en Descartes con el giro, en apariencia insignificante, pero no por ello menos funesto, que convierte al ego en substantia cogitans, en la humana y separada mens sive animus, $y$ en punto de partida de conclusiones regidas por el principio de causalidad; en una palabra, el giro mediante el cual Descartes llegó a ser el padre del absurdo realismo trascendental (cosa que todavía no puede llegar a verse claramente aquí) $).{ }^{5}$

Y, efectivamente, las Meditaciones cartesianas no vuelven a enfrentarse con los prejuicios que planteara la filosofía de Descartes. Es La crisis de las ciencias europeas, la última obra publicada por Husserl, la que plantea con amplitud todo el problema de los prejuicios que habían gravitado sobre el pensamiento moderno y, en particular, los que habían tenido su origen en la filosofía cartesiana. Como ya se ha anticipado, La crisis constituye un planteamiento de la fenomenología plenamente consciente de su situación histórica, de su sentido como culminación del telos que había dominado en la historia de Europa. Y, por tanto, tenía que tratar con detenimiento la superación de los prejuicios que habían pesado en su evolución o que la habían desviado. "Pensar por uno mismo, ser un filósofo independiente con la voluntad de liberarse de todos los prejuicios, esto exige de uno que tome conciencia de que todo lo que se tiene por obvio es prejuicio, de que todos los prejuicios son oscuridades que provienen de una sedimentación tradicional y no solamente, pongamos por caso, juicios de verdad incierta, y que esto vale ya para la gran tarea, para la idea que se llama filosofia. $\rangle^{6}$

Ciertamente, La crisis constituye una denuncia sistemática y abrumadora de los prejuicios que han pesado sobre la filosofía moderna, entre los cuales el dualismo "alma-cuerpo" cartesiano constituye un caso más, aunque de indudable resonancia filosófica. ${ }^{7}$ Más bien son ahora Galileo y los teóricos de las ciencias de la naturaleza los que cargan con las culpas de 
haber iniciado el gran prejuicio del «objetivismo», es decir, de la fe en el logro de un conocimiento absoluto de la realidad material, contrapuesta a una realidad mental a la que, sin embargo, se intentó trasplantar la metodología fisicalista. «De este modo, la psicología fue cargada de antemano con la tarea de ser una ciencia paralela [a la ciencia natural matemática] y con la siguiente concepción: que el alma - su tema- sea algo real en el mismo sentido que la naturaleza corpórea, que constituye el tema de la ciencia natural. En tanto que este prejuicio de siglos no quede desvelado en su sinsentido, no habrá ninguna psicología que sea ciencia de lo realmente anímico, precisamente aquello que tiene sentido originariamente a partir del mundo de la vida $[\ldots] . x^{8}$

Por tanto, no fue sólo el Husserl de la etapa inicial de las Investigaciones lógicas o de las Ideas para una fenomenología pura el que se enfrentó abiertamente con los prejuicios, apelando a la intuición de las esencias y de los principios que en ellas radican y que exigen unas condiciones $a$ priori para toda actividad de la conciencia o para los respectivos estados de cosas objetivos. También el Husserl tardio de La crisis de las ciencias europeas mantiene el rechazo de los prejuicios, apelando de nuevo al a priori de las funciones de la subjetividad trascendental, que se plasman en las situaciones objetivas del mundo, cuyas estructuras manifiestan una necesidad y universalidad que las coloca por encima de la transitoriedad histórica propia de los prejuicios. Estos se caracterizan por ser productos erróneos del pensamiento humano porque, en cada caso, se han originado a partir de la infracción de un principio trascendental que dimana del $a$ priori universal de la correlación entre la conciencia y la objetividad. El mentalismo cartesiano de la res cogitans se descubre como un prejuicio desde el momento en que se le contrasta con el puro funcionalismo intencional de la subjetividad. Así como el objetivismo fisicalista descubre su falsía en la medida en que oculta la vinculación de todo objeto con las funciones de la conciencia que condicionan y configuran su presencia. Es decir, en la impugnación husserliana de los prejuicios pesan los motivos desplegados en su lógica formal y trascendental. La vigencia del pasado en el presente no constituye en modo alguno una circunstancia perturbadora, como no se trate de un pasado que arrastre infracciones lóricas y que, por este motivo, opere como un prejuicio dañino para el presel_- jue lo absorbe. Pero el interés que ahora, en La crisis de las ciencias europeas, muestra Husserl hacia los sedimentos del pasado que han calado en nuestro mundo actual, sedimentos que tienen mucho en común con lo que Gadamer llamaría "prejuicios", no le dispensa de su adhesión definitiva hacia los principios lógicos que marcan las normas fundamentales de toda forma de conducta consciente, teórica o práctica. 


\section{4. ¿Es un prejuicio el apriorismo?}

Por consiguiente, el rechazo de los prejuicios realizado por Husserl se basa en su apriorismo. En las Investigaciones lógicas se trata del a priori de los principios analíticos o de las leyes vitando contrasentido que rigen el juicio y los estados de cosas intencionales por él objetivados. En la Filosofía como ciencia rigurosa y en las obras posteriores, en especial en La crisis de las ciencias europeas, es el a priori de la lógica trascendental, el de la correlación intencional entre subjetividad y mundo, el que marca las exigencias que permiten descubrir, como infracciones lógicas, la existencia de los prejuicios.

Sin embargo, es importante destacar el diferente papel que en ambas etapas juega la historicidad. Pues es manifiesto que en los prejuicios denunciados en las Investigaciones lógicas, es decir desde la perspectiva de una lógica formal que atiende el cumplimiento de las leyes que rigen el juicio y sus estados de cosas objetivos, la historia cuenta bien poco: el psicologismo atacado por Husserl es contemporáneo del logicismo puro que el defiende. La existencia de psicologistas en etapas anteriores es puramente anecdótica y no tiene ninguna importancia en su discusión. $Y$ es que la lógica formal no sabe nada de la historicidad que pudiera afectar a los juicios y a los estados de cosas por ella estudiados: los urecorta" de las situaciones mundanas en que pudieran darse, les priva del tiempo histórico que es solidario de esa mundanidad y los trata desde la perspectiva de una legalidad formal, la que es propia del juicio o del enunciado, que no incluye ninguna conexión con la historicidad que es propia de su mundo.

En cambio, en la impugnación de los prejuicios que se inicia con La filosofía como ciencia rigurosa y que alcanza su pleno desarrollo en $\mathrm{La}$ crisis de las ciencias europeas, el a priori a que apela Husserl es el de la lógica trascendental, es decir, de la lógica que trata de la vinculación intencional entre la subjetividad y el mundo. Y con ello la historicidad tiene que ocupar una posición privilegiada en la discusión de los problemas, en concreto en la discusión de los prejuicios. El mundo significa la totalidad de los seres, el universo de los objetos o de las situaciones que se despliegan ante un sujeto. Como «horizonte» espacial y temporal, el mundo no sólo abarca la totalidad de los objetos que se extienden en el espacio y que se anuncian en los ámbitos infinitos que se vislumbran más allá de sus límites. Es también el universo histórico, el horizonte de una temporalidad infinita que se despliega en el pretérito y en el futuro sin límites de la mundanidad. Por tanto, los prejuicios que ahora se combaten tienen un marcado sentido histórico. Se les sitúa en concreto en los inicios de la Edad Moderna, en los albores del pensamiento platónico o en los tiempos de la Ilustración. Y ello es así porque su vigencia perturbadora no acaece en estados de cosas intemporales, sino en el presente de una filosofía que 
se halla en crisis, en la misma crisis que atenaza a Europa y que pone en peligro una racionalidad que proviene de los tiempos lejanos en que nació el logos filosófico helénico. Aunque el rechazo de los prejuicios se siga fundando en un apriorismo, en el de los principios trascendentales que expresan la correlación intencional entre sujeto y mundo, es decir, aunque sea una impugnación basada en motivos trascendentales, no se puede silenciar que concierne a prejuicios que tienen un momento histórico y que provienen de un pasado determinado.

Esta perspectiva histórica del rechazo de los prejuicios realizado en las Meditaciones cartesianas y en La crisis de las ciencias europeas se hace aún más clara si se tiene en cuenta el papel que en ambas obras juega el mundo de la vida concreto como "punto de partida" o "hilo conductor" de los análisis fenomenológicos. A diferencia del mundo circundante de las Ideas para una fenomenología pura, que significa sólo el horizonte de las experiencias que se da previamente a toda investigación científica, el mundo de la vida concreto está "revestido" y "traspasado" por los sedimentos de las construcciones teóricas o prácticas que en él se han realizado en los momentos previos de su historia.

En La crisis de las ciencias europeas alcanza todo su desarrollo esta concepción del mundo de la vida concreto que ya se había adelantado en los parágrafos 43 y 58 de las Meditaciones cartesianas. El que se trate del mundo dado en la wactitud natural», es decir, en la experiencia cotidiana que tenemos de las cosas y que opera como "suelo" (Boden) para las construcciones científicas de cualquier índole, no impide que en él se hayan incrustado los productos de las actividades culturales que de él se hayan ocupado previamente. Cualquier persona que viva en una sociedad culta de nuestro tiempo se enfrenta con el espectáculo del cielo visible sabiendo que está formado por una atmósfera gaseosa, que los astros que contempla no giran en torno suyo, sino que es la Tierra la que rueda en torno a su eje, etc. Es decir, en el mundo de la vida concreto de nuestro tiempo se han sedimentado las teorías que forman nuestra comprensión básica de la realidad. "Por ello la ciencia, en tanto que es una realización de las personas pre-científicas, de las individuales y de las que se agrupan en las actividades científicas, pertenece ella misma al mundo de la vida. Ciertamente sus teorías, las construcciones lógicas [die logischen Gebilde] no son cosas del mundo de la vida como lo son las piedras, las casas, los árbóles.» Son «unidades ideales de significación" que pertenecen a «esta unidad concreta del mundo de la vida, cuya concreción, por tanto, alcanza más que la de las cosas".?

Es evidente que la teoria del mundo de la vida concreto abre paso a la doctrina de Gadamer sobre el prejuicio. Las eincrustaciones" culturales que penetran en las cosas y que son los «sedimentos" de las construcciones teóricas realizadas en tiempos anteriores, tal como se exponen en la "Introducción» de Experiencia y juicio y en los análisis que se realizan en 
La crisis sobre la fusión del "mundo objetivo" constituido por las ciencias con el mundo de la vida originario formado por las experiencias, todo ello depara una explicación fenomenológica de la vigencia de los prejuicios que satisfacía plenamente las pretensiones de Gadamer. $\mathrm{O}$ que, cuando menos, daba una justificación fenomenológica a su afirmación de que la "comprensión" de las cosas y su "interpretación" era posible gracias a la absorción de los prejuicios por las situaciones de que nos ocupamos. Dicho con términos husserlianos, la estructura noemática de las cosas se constituye no sólo mediante la intelección actual de su componente empírico "típicamente" organizado, sino mediante el "sedimento" de las intelecciones previas que, en forma de prejuicios, es decir, como un "saber previo", se ha sedimentado sobre el sentido de esas cosas y lo ha enriquecido en forma de nuevas capas noemáticas.

También se podría pensar que Gadamer no hubiera objetado nada a la tesis husserliana de que ese mundo de la vida concreto, distinto en cada momento de la historia, debe ser el "punto de partida" para cualquier proceso hermenéutico que intente realizar una comprensión de los productos de la actividad humana o de ésta misma. Sin embargo, si se tiene en cuenta que, en el caso de Husserl, ese "punto de partida" lo ha sido en buena medida para denunciar los "prejuicios" que han pesado sobre la filosofía moderna, deberán enfriarse nuestros impulsos en favor de una aproximación excesiva entre Husserl y Gadamer. Es decir, aunque la teoría husserliana de la constitución del mundo de la vida concreto, absorbiendo los mundos objetivos o los mundos culturales que surgen en la historia, pueda ser considerada como un respaldo fenomenológico para la teoría de Gadamer sobre la formación de las "tradiciones» y del sentido de las cosas en virtud de los prejuicios que en ellas calan, no se puede olvidar el trato polémico que éstos recibieron por parte de Husserl. Y que, como "punto de partida" para una fenomenología que a partir de ellos se desarrollaba, eran objeto de un tratamiento crítico realizado desde unos principios lógicos que fijan las condiciones fundamentales para toda actividad de la conciencia y para toda objetividad. Por tanto, las construcciones históricas que revisten el mundo de la vida concreto (construcciones que Gadamer hubiera llamado "prejuicios" en tanto que provienen del pasado histórico) son un "punto de partida" o un ahilo conductors ${ }^{10}$ en un sentido que Gadamer no ha aceptado. Pues están sometidas a un «desmantelamiento» (eine Abbau) que debe dejar al descubierto las formas "típicas» de la experiencia y las "objetividades inteligibles" que subyacen a toda construcción histórica y a los prejuicios inscritos en las tradiciones que se han grabado en el mundo de la vida. La fenomenología podrá poner así de manifiesto "el a priori universal de la correlación» que se da entre todo objeto mundano y la subjetividad trascendental que condiciona su presencia." $\mathrm{O}$ afirmará la peculiaridad originaria de la somaticidad [die Leiblichkeit] del cuerpo 
vivo que cada sujeto tiene y que se funde con la experiencia del mundo de la vida originario que genera el juicio, dejando fuera de juego el prejuicio de la dualidad entre cuerpo y mente.

Es decir, el mundo de la vida concreto carece de sentido si no se le entiende como fase inicial de un proceso fenomenológico que desemboca en el mundo de la vida originario, en el mundo primordial que, según la terminologia de las Meditaciones cartesianas, es vivido por cada individuo como mundo "propio", y en los principios lógicos formales y trascendentales que hacen posible la intelección de las cosas. De él arranca la fenomenología que indaga las estructuras originarias de la experiencia, las que se puede descubrir cuando se haya "desmantelado" el mundo de la vida concreto, dejándolo desnudo de las construcciones ideales que forman la objetividad científica y el mundo de la cultura. Esa indagación es la que desemboca cn el mundo de la vida originario de Experiencia y juicio y, en definitiva, cuando se le vincula con la "somaticidad viva" del sujeto, en el mundo primordial de las Meditaciones cartesianas. Pero sobre estos mundos, cuyo talante empírico es manifiesto, se ciemen las exigencias a priori de los principios y de las esencias que marcan las condiciones necesarias y universales que debe cumplir toda objetividad $y$, por consiguiente, toda conducta humana objetivante.

Este es el punto en el que la divergencia entre Husserl y Gadamer se hace más ostensible. Pues la vigencia de cste a priori, que radica en las esencias que se hacen inteligibles en todo acto de conciencia, es fundamental en el análisis fenomenológico de Husscrl. Como se ha venido indicando en este trabajo, es la piedra de toque por la que puede denunciar la existencia de prejuicios que trastornan el curso de la filosofía. Por consiguiente, en la medida en que los prejuicios puedan introducir anomalías en el pensamiento humano o sean el resultado de actitudes patéticas, en el fondo irracionales, el a priori de las leyes lógicas, como garantía de una rigurosa racionalidad, ha de ser un elemento fundamental para la erradicación de los prejuicios. Con su teonía del mundo de la vida concreto Husserl pudo mostrar una admirable comprensión de lo que significa la historia en la construcción de los productos culturales o ideales que revisten ese mundo. Pero ello no le obligó nunca (al menos formalmente) a renunciar a su viejo propósito de hacer de la fenomenología una ciencia rigurosa, capaz de discernir entre las construcciones ideales que se ha dado en la historia, que han abierto carnino a una comprensión rigurosa del mundo, y aquellas otras construcciones teóricas o prácticas que, en forma de prejuicios, sólo han sido un impedimento para el logro de la ciencia o de la filosofía. Pues bien, en esa tarea crítica frente a los prejuicios el a priori fue siempre para Husserl un arma decisiva. Con él se ponían al descubierto las irregularidades lógicas que hacen del prejuicio un factor negativo en el progreso de la ciencia. 
Sin embargo, hay que preguntar hasta qué punto estaba autorizado Husserl a mantener esa rígida oposición entre los prejuicios y la validez a priori de los principios lógicos. Pues a partir del planteamiento dado al mundo de la vida concreto como "punto de partida" e "hilo conductor» de las indagaciones fenomenológicas, era necesario precisar la función que tiene lo a priori en relación con la historicidad que mueve a los mismos prejuicios. Cuando menos, se imponía considerarlo como un factor historico desde el momento en que la historicidad estaba inscrita en el mundo que facilitaba su hallazgo. Es decir, lo a priori no reside en un mundo de ideas celestes, que se elevan por encima de los avatares de la historia. No pertenece a una conciencia o a una subjetividad puras, que nada saben de las peripecias históricas. Si la historicidad se ha convertido en una pieza fundamental de la fenomenología es porque registra la estructura esencial de ese mundo de la vida concreto y de la subjetividad que lo constituye intencionalmente. Por consiguiente, no tiene sentido la vigencia de un $a$ priori fuera de la historia, en mundos etéreos donde sólo gobieme una razón aséptica para todo acontecimiento temporal histórico. Lo que valga a priori ejerce su vigencia dentro de las situaciones históricas concretas, como antídoto de prejuicios o como condición de la legitimidad lógica de lo objetivo y de la conducta humana racional. El a prioni de las Ideas para una fenomenologia pura, que valía para una subjetividad trascendental ajena a los procesos históricos y para un mundo circundante que sólo registraba las experiencias que son la base para el conocimiento científico riguroso, ha desaparecido de la escena de la fenomenología husserliana. Ahora está en juego un a priori metido de lleno en la historia, que vale para un mundo de la vida concreto henchido de productos históricos $\mathrm{y}$, por tanto, para la subjetividad trascendental cuyo dinamismo intencional es responsable de la constitución de esa mundanidad histórica. Es decir, de lo a priori ha quedado en pie su «fundamentalidad», su vigencia como repertorio de objetividades que trazan las líneas fundamentales de una ontología o de valores que deciden los motivos radicales de una conducta práctica. $O$, visto desde la perspectiva de la subjetividad que intencionalmente hace posible la presencia de esas objetividades y la validez de esos motivos, lo a priori representa las funciones esenciales de la conciencia cognoscitiva o práctica que constituye el espectáculo universal de las situaciones en que el hombre actúa. Lo que ha quedado malparado es el supuesto de que el a priori que se descubra en cada momento de la historia, incluso el que ha sido reclamado por la fenomenología de nuestro tiempo, sea universal y necesario en el sentido más radical de estos términos. Asunto distinto es que, en cualquier caso, el a priori que tenga vigencia en un mundo de la vida concreto depare la trama lógica desde la que se intente comprender cualquier otro mundo acaecido en la historia. Es decir, proporcione la clave mediante la cual se realice la traducción de un mundo 
ajeno al que es propio de un sujeto o de una colectividad deterninada. $\mathrm{Y}$ que desde ese a priori se adviertan las diferencias que median entre los diferentes mundos o las que se registran entre los principios que fueron asumidos como un a priori por sus respectivos sujetos. Claro está, son diferencias que se perfilan desde la perspectiva dcl a priori que pone en juego el sujeto que lo vive y que no puede desasirse de él, saliendo de su esfera de vigencia.

Ahora bien, si esto es así, ¿en qué medida se puede considerar lo a priori un "prejuicio"? No se trata de una pregunta inocente que se limite a sugerir que un principio válido a priori "va por delante» de los juicios que rige o tiene una validez que, por ser universal, se anticipa de alguna manera a cualquier otro juicio que le obedezca.

Lo que se está preguntando es si ese mismo sentido de lo que pretende valer a priori está sujeto a los avatares de la historia, a pesar de su pretensión de ser una ley esencial vigente universal y necesariamente. Y la pregunta obedece al hecho de que Husserl reclamó una primacía metodológica del mundo de la vida concreto para la búsqueda de lo a priori. Es decir, por vez primera en la historia de la problemática de lo a priori se advirtió que su hallazgo no acaece en un reino utópico de puras esencias, que pudieran ser descubiertas mediante una pirueta de la razón que la situara más allá de todo mundo histórico. El a priori alcanzado por cualquier indagación fenomenológica es el que se descubre a partir de un mundo de la vida concreto, históricamente realizado, que constituye el "punto de partida» y el "hilo conductor" para sus investigaciones.

Con esto se está sugiriendo que la historicidad que, velis nolis, le llega a lo a prioni desde el mundo de la vida concreto que es el preámbulo obligado para su hallazgo, lo hace afín de alguna manera a los prejuicios. Así como éstos son históricos porque expresan la vigencia del pasado en las creencias que dominan en nuestro presente, lo a priori tiene su peculiar historicidad porque sólo puede ser planteado a partir de mundos de la vida concretos que son esencialmente históricos. Sin embargo, aunque se está proponiendo una historicidad en lo a priori, la que proviene de su vinculación metodológica con el mundo de la vida concreto que facilita su hallazgo o que le da cumplimiento, sería injusto omitir las diferencias profundas que lo distinguen de los prejuicios. Lo a priori reclama una validez privilegiada en tanto que es fundamento de la racionalidad que se plasma en un mundo concreto. Y ello le confiere un carácter esencialmente lógico, una racionalidad primaria.

Por consiguiente, lo a priori posee la racionalidad primigenia de lo que es el fundamento esencial de cualquier forma de objetividad. Pero, al mismo tiempo, la suficiencia que le corresponde, al no derivar de instancias previas que le otorgasen una justificación básica, concede a lo a priori una evidencia privilegiada. $O$, dicho en terminología husserliana, las esencias a priori son objeto de una intuición intelectual. La «unidad» de cual- 
quier objeto es intuida como una condición necesaria de su objetividad, lo mismo que el «ser» y el «no ser» apofánticos se contradicen como formas opuestas de la veracidad.

Con otras palabras, los prejuicios valen en tanto que una tradición los mantiene en vida como piezas fundamentales de una comprensión del mundo. En cambio, lo a priori obtiene su fuerza de su función lógica en un sistema racional, en el que opera como la dimensión radical de las cosas. Por consiguiente, se puede admitir que el impacto de la historia haya podido debilitar la universalidad y necesidad de lo que vale a priori, reduciéndolas a una "pretensión" o "presunción" que tiene vigencia en un mundo concreto, contando con la cual se puede entablar un diálogo con otras culturas hasta que se llegue a situaciones conflictivas que hagan suponer que en esas culturas tienen validez otros principios lógicos que pudieran ser su propio a priori. Sin embargo, mientras se mantenga el sentido básico de ese término, lo a priori valdrá como el fundamento racional, el sistema de principios lógicos que en cualquier momento cultural histórico decide las líneas maestras de su comprensión.

$Y$, en definitiva, aunque la entrada en escena de la historicidad haya podido debilitar el a priori husserliano, anulando su validez universal y necesaria sensu stricto y reduciéndola a una "pretensión" que le permita indagar su vigencia en otros ámbitos culturales, con todo la teoría husserliana del a priori posee un sentido lógico que no es posible eliminar y que la diferencia de los "prejuicios" gadamerianos: sea el que se quiera el alcance de su vigencia en el curso de la historia, lo que en cada etapa de ésta vale como fundamento lógico de sus construcciones teóricas o prácticas es lo que puede o debe ser denominado a priori. En cambio, la eficacia de los prejuicios no posee el talante lógico de las esencias o de los principios a priori. Es tan sólo el de una "efectividad histórica».

\section{NOTAS}

1. La crisis de las ciencias europeas, $I, \S 5$, p. 12. (En adelante se citarán las obras de Husseri según la edición Husserliana de Martinus Nijhoff.)

2. Id., I, \& 7, p. 16 .

3. Meditaciones cartesianas, $\S 2, \mathrm{p} .47$.

4. $I d ., \S 3, \mathrm{p}, 48$.

5. Id., $\$ 10$, p. 63 .

6. La crisis de las ciencias enropeas, $\S 15$, p. 73 .

7. Id. $\S 60$, p. 216 .

8. Ibid.

9. La crisis de las ciencias europeas, \$ 34-e, p. 132.

10. $I d . . \$ 50$ y 51 , pp. 175 y 177 .

11. $l d ., \S 46$, p. 161 . 